\title{
Türkiye'de üniversite öğrencilerinin cinsel yolla bulașan hastalıklar konusunda bilgi düzeyi: Sistematik derleme
}

\author{
Knowledge level about sexually transmitted diseases among university \\ students in Turkey: A systematic review
}

Fatma Yıldırım, Nülüfer Erbil

\section{öz}

AMAÇ: Bu çalışma, lisans eğitimi alan üniversite öğrencilerinin cinsel yolla bulaşan hastalıklar $(\mathrm{CYBH})$ hakkında bilgi düzeylerine ilişkin çalışmaların sistematik olarak incelenmesi amacıyla yapılmıştır.

GEREC ve YÖNTEMLER: $\mathrm{Bu}$ sistematik derleme, 10.11.201915.12.2019 tarihleri arasında, 2014-2018 yılları arasında yayınlanmış olan Türkçe makaleler alınmıștır. Konu ile ilgili makalelere ulașmak için; "cinsel yolla bulaşan hastalıklar, gençler ve üniversite öğrencileri" anahtar kelimeleri kullanılarak, Google Akademik, Ulakbim, Türk Medline ve Dergi Park arama motorlarından yayın dili Türkçe olan makaleler taranmıştır. Tarama sonucunda 4263 makaleye ulaşıldı ve dâhil edilme kriterlerine uygun 12 makale alınmıştır.

BULGULAR: İnceleme sonucunda sağlık ile ilgili bölümdeki öğrencilerin çoğunluğunun daha önceden CYBH konusunda bilgi aldığı saptanmıştır. Daha önceden bilgi sahibi olanların çoğunluğu CYBH konusunda bilgi düzeyi yeterli bulunmuştur. Sağlık ile ilgili bölümdeki öğrencilerin çoğunlukla bilgi düzeyleri orta ya da yeterli düzeyde belirlenmiştir. Öğrenciler arasında en çok bilinen CYBH'nin AIDS olduğu bulunmuştur.

SONUÇLAR: Öğrencilerin çoğunluğunun CYBH konusunda bilgi düzeylerinin yetersiz olduğu belirlenmiştir. Genel olarak bilgi düzeyi orta ve yeterli düzeyde olan öğrenciler sağlık ile ilgili bölümdeki öğrencilerden oluşmaktadır. Öğrencilere CYBE hakkında bilgilendirme yapılması ve ileri araştırmalar planlanması önerilir.

Anahtar Kelimeler: cinsel yolla bulaşan hastalıklar, gençler, üniversite öğrencileri

\section{Gíriș}

Cinsel Yolla bulaşan hastalıklar (CYBH), toplumun sağlığını olumsuz etkileyen ciddi hastalıklardır. ${ }^{[1]}$ Pelvik inflamatuar hastalık, infertilite, yenidoğanda körlük, kanser,

${ }^{7}$ Hitit Üniversitesi Sağlık Bilimleri Fakültesi, Çorum, Türkiye

${ }^{2}$ Ordu Üniversitesi Sağıı Bilimleri Fakültesi, Ordu, Türkiye

Yazışma Adresi/ Correspondence:

Asistan Fatma Yıldırım

Bahçelievler Mah., Mehmet Akif Ersoy 3.cad., No: 10/2, 19600 Çorum, Türkiye

Tel: $\quad$ +905466742445

E-mail: fatmadmryldrm@gmail.com

Gelis/ Received: $\quad 01.03 .2021$

Kabul/ Accepted: 14.04 .2021

\section{ABSTRACT}

OBJECTIVE: The aim of this study was to investigate the systematic review of the knowledge level of sexually transmitted diseases (STDs) among university students.

MATERIAL and METHODS: This systematic review was conducted by examining the Turkish articles published between 10.11.201915.12.2019 between 2014-2018 to reach related articles: "sexually transmitted disease, young people and university students" keywords were searched and published in Google Scholar, Ulakbim, Türk Medline and Dergi Park search engines. As a result of the screening, 4263 articles were reached and 12 articles were complied with the inclusion criteria. RESULTS: As a result of the examination it was found that the students in the health department generally received information about STDs beforehand. The majority of those who had previously received information about STDs. The majority of those who had previous knowledge were found to have sufficient knowledge of STD. The knowledge level of the students in the health department was found to be moderate or sufficient. Among the students, AIDS was the most known STD.

CONCLUSION: Most of the students had insufficient knowledge about STDs. In general, students with moderate and sufficient level of knowledge consisted of students in the health department.

Keywords: sexually transmitted diseases, young people, university students

ektopik gebelik ve ölüm gibi sosyal ve hayati sorunlara neden olan sonuçlarından dolayı CYBH önem taşımaktadır.

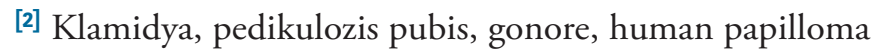
virüs enfeksiyonu, skabies, mantar, trikomonas, hepatit C, sifiliz, lenfogranüloma venerum, herpes, hepatit $B$ ve AIDS CYBH'den bazıları olup 30'dan fazla CYBH bulunmaktadır. ${ }^{[1]}$

Gençlik dönemi içerisinde yaşanan hızlı fiziksel ve hormonal değişimlerin getirdiği adaptasyon sorunları nedeniyle istenmeyen gebelikler ve zorunlu genç yaşta bebek sahibi olma gibi beklenmedik ve istenmedik toplumsal sorunların yanı sıra Acquired Immune Deficiency Syndrome (AIDS), isteyerek yapılan düşükler ve $\mathrm{CYBH}$, hastalık ya da bireyin 
kendi ölümü ile sonuçlanabilen birçok sorunların da ortaya çıktığı tespit edilmiştir. ${ }^{[3]} \mathrm{Bu}$ nedenle üreme ve cinsel sağlık ile ilgili yaşanan sorunlar gençlik döneminde ciddi bir anlam kazanmakta olup, tüm yaşam boyunca sağlık sorunları içinde önemli bir yer tutmaktadır. ${ }^{[4]} \mathrm{Bu}$ dönem çocukluktan yetişkinliğe geçiş dönemi olup, sağlık alışkanlıklarının ve cinsel davranışların kazanıldığı ve şekillendiği, son derece önemli bir dönemdir. ${ }^{[5]}$

CYBH zor tanı konulması, sık görülmesi ve tedavisinin uzun süreli olması nedeni ile insan sağlığı açısından son derece önemlidir. Erken yaşta kontrolsüz, sağlıksız ve uygun olmayan cinsel ilişkiye başlayan kişilerde, yeterli olmayan ya da yanlış bilinen bilgiler nedeni ile bu hastalıkların önlenmesi daha zor olmaktadır. ${ }^{[6]} \mathrm{Bu}$ nedenle tedavi edici yöntemlerden ziyade koruyucu yöntem ve danışmanlık hizmetlerinin ön planda tutulması daha da anlam kazanmaktadır. ${ }^{[7]}$

CYBH'nin çoğunlukla görüldüğü yaş döneminin cinsel aktivitenin başladığı yaşla ilgili olduğu bilinmektedir. Sosyodemografik etkenlerin yanı sıra bu dönemde bulaşmayı en fazla artıran sebebin, gençlerin yeterince doğru bilgi sahibi olmamasından kaynaklandığı bilinmektedir. ${ }^{[7]}$

$\mathrm{Bu}$ sistematik derlemede üniversite öğrencilerinin $\mathrm{CYBH}$ konusunda bilgi düzeylerine ilişkin yapılmış çalışmaların incelenmesi amaçlanmıştır.

\section{GEREÇ Ve YÖNTEMLER}

Sistematik derleme niteliğinde olan bu çalışmanın yapılmasi ve raporunun hazırlanmasında Sistematik Derleme veya Meta Analiz Araştırma Raporunun Yazımında Bulunması Gereken Maddelerle İlgili Kontrol Listesi (PRISMA) protokolü takip edilmiştir. ${ }^{[8]} \mathrm{Bu}$ sistematik derlemede oluşabilecek bias riskini azaltmak amaciyla literatür tarama, makale seçimi, veri çekme ve makale kalitesinin değerlendirilmesi işlemlerinin her bir aşaması her iki araştırmacı tarafından bağımsız olarak yapılmış ve görüş birliğine varılmıştır.

\section{Tarama Stratejisi}

Bu çalışmaya Türkiye'de yapılmış, 2014-2018 yılları arasında yayınlanmış, yayın dilinin Türkçe olan, tam metnine ulaşılan, araştırma örneklemi üniversite öğrencileri olma kriterlerini karşılayan çalışmalar alınmıştır. Çalışmada, 10.11.201915.12.2019 tarihleri arasında Google Akademik, Ulakbim, Türk Medline ve Dergi Park veri tabanlarından tarama yapılmıştır. Taramada "cinsel yolla bulaşan hastalıklar", "üniversite ögrencileri" ve "gençler" anahtar kelimeleri kullanılmıştır. Sistematik derlemeye yukarıda belirtilen kriterlere uyan 12 çalışma alınmıştır. Taranan araştırmaların seçimi ve seçilme süreci şekil l'de verilmiştir.

Sistematik derlemeden dışlama kriterleri ise, derleme ya da kalitatif çalışma olması ve özet metin olmasıdır.

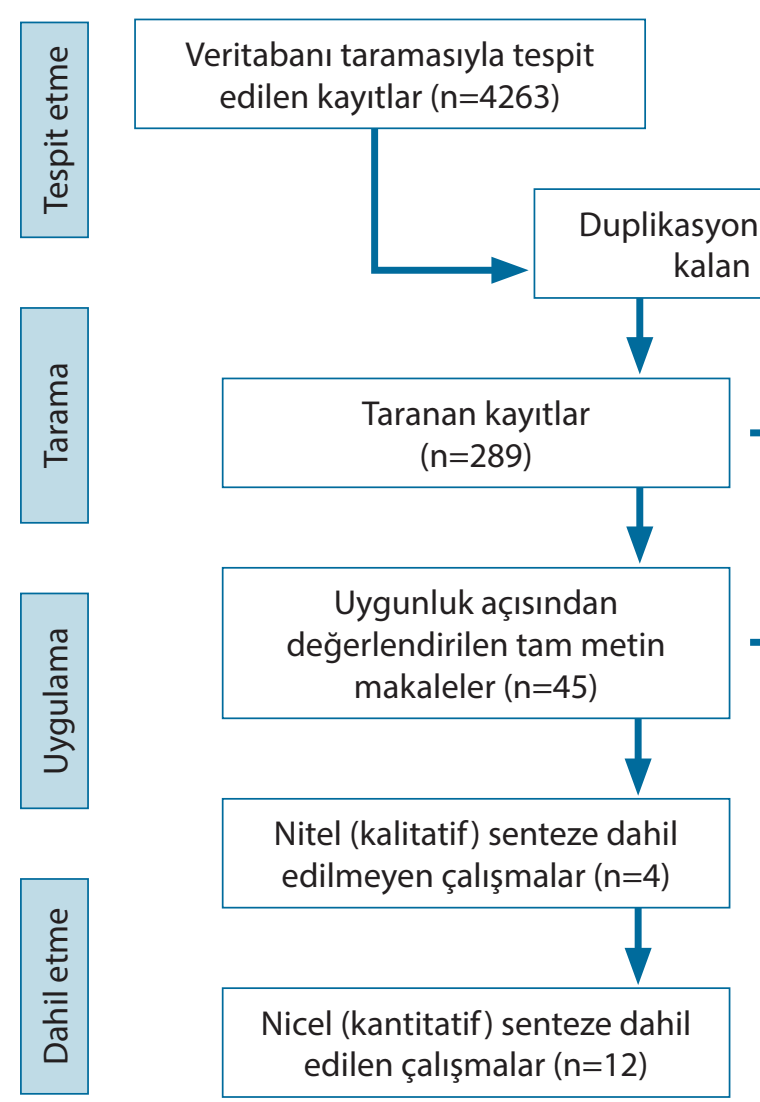

Diğer kaynaklardan tespit edilen ek kayıtlar $(n=0)$ 


\section{Verilerin Çekilmesi}

Araştırmada verilerin elde edilmesi için araştırmacılar tarafından geliştirilen bir veri çekme aracı kullanılmıştır. Bu veri çekme aracı ile araştırmaların yazar ve yayın yılı, amaCl, veri toplama araçları, örneklem hacmi, temel bulgular ve lisans düzeyindeki öğrencilerin CYBH hakkındaki bilgi düzeylerinin belirlenmesi hakkındaki verilerin elde edilmesi sağlanmıştır.

\section{Çalıșmaların Metodolojik Kalitesinin Değerlendirilmesi}

Bu sistematik derlemeye dahil edilen araştırmaların metodolojik kalitesi Joanna Briggs Institute tarafindan yayınlanan, analitik kesitsel araştırmaların kalite değerlendirmesi 8 maddeli kontrol listesi ile yapılmıştır. Bu listede bulunan her madde "evet, hayır, belirsiz ve uygulanmaz" olarak değerlendirilmektedir. ${ }^{[9]}$ Her bir araştırma için tespit edilen durum Tablo 1'de verilmiştir.

\section{Verilerin Analizi}

Verilerin değerlendirilmesi, araştırmacılar tarafından hazırlanmış olan veri özetleme formu ile yapılmıştır. Veri özetleme formunda; çalışmanın yazarları, yılı, şekli, amacı, veri toplama araçları, örneklemi, bulguları ve sonuçları yer almıştır (Tablo 1).

\section{BULGULAR}

Bu sistematik derlemede, 2014-2018 yılları arasında yayınlanmış olan 12 makale yer almıştır. Bu 12 çalışmanın toplam 4254 üniversite öğrencisinden oluşan örnekleme sahip olduğu belirlenmiştir. Karasu ve ark.'nın (2017) ${ }^{[10]}$ ve Babaoğlu ve ark.'nın (2016) ${ }^{[11]}$ çalışmasında öğrencilerin yaşları arttıkça CYBH konusunda bilgi düzeylerinin arttığı belirtilmiştir. Bakır ve Kızılkaya Beji'nin (2015) çalışmasında öğrencilerin \%36'sı daha önce cinsel sağlıkla ilgili eğitim aldığını belirtmiştir. ${ }^{[12]}$ Çalışkan ve ark.'nın (2015) ${ }^{[4]}$ çalışmasında öğrencilerin \%75,8'inin, Elkin'in (2015) ${ }^{[13]}$ çalışmasında \%44,7'sinin, Akça ve ark.'nın (2016) ${ }^{[14]}$ çalışmasında \%94,2'sinin, Aykan ve ark.'nın (2017) ${ }^{[15]}$ çalışmasında \%48,2'sinin, Akalpler ve ark.'nın (2015) ${ }^{[3]}$ çalışmasında \%56,5'inin, Vural ve ark.'nın (2015) ${ }^{[16]}$ çalışmasında \%72,9'unun daha önce cinsel sağlık konusunda bilgi aldıkları bildirilmiştir. Bilgi alanlardan çoğunluğun sağlık ile ilgili okullarda eğitim gördüğü bildirilmiştir. ${ }^{[10,13,14,16,17]}$ Öğrencilerin CYBH bilgisini nereden edindikleri sorulduğunda, Akça ve ark. (2017) ${ }^{[14]}$ öğrencilerin \%80,8'inin, Akalpler ve ark. ${ }^{[15]}$ öğrencilerin \%34,4'ünün okuldan bilgi aldıklarını belirtmişlerdir. Akça ve ark. ${ }^{[14]}$ öğrencilerin \%51'inin, Avcıkurt ve ark. $(2017)^{[18]}$ öğrencilerin \%78,5’inin, Karasu ve ark. (2017) ${ }^{[10]}$ öğrencilerin $\% 48,8$ 'inin internet ve televizyon üzerinden bilgi edindiğini belirtmiştir. Çalışkan ve ark.'nın (2015) ${ }^{[4]}$, Karasu ve ark.'nın (2017) $)^{[10]}$ ve Akalpler ve Eroğlu’nun (2015) ${ }^{[3]}$ çalışmalarında CYBH konusunda daha önceden bilgi alanların almayanlara göre doğru cevap verme durumları istatistiksel olarak anlamlıdır $(\mathrm{p}<0,05)$.

Sistematik derlemeye alınan çalışmalarda, CYBH bilgi testine göre doğru yanıt puan ortalaması, Akça ve ark.'nın (2016)

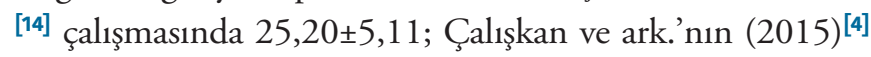
çalışmasında 24,96 4,54; Bakır ve Kızılkaya Beji'nin (2015) ${ }^{[12]}$ çalışmasında $16,64 \pm 7,00$ ve Vural ve ark.'nın $(2015)^{[16]}$ çalışmasında 20,35 $\pm 6,07$ bulunmuştur. CYBH bilgi testinden en yüksek 36 puan alındığı dikkate alındığında ${ }^{[19]}$, doğru yanıt puan ortalamalarının düşük olduğu görülmektedir.

Bakır ve Kızılkaya Beji’nin (2015) ${ }^{[12]}$ çalışmasında öğrencilerin $\% 36,0{ }^{\prime}{ }_{1}$ cinsel ilişki deneyimi yaşamış, deneyimi olanların da \%38,2'si korunmadığını belirtmiştir. Ayrıca cinsel deneyimi olan öğrencilerin CYBH bilgi testine göre doğru yanıt ortalamaları daha yüksektir. ${ }^{[12]}$ Akalpler ve Eroğlu'nun (2015) çalışmasında ise cinsel ilişki deneyimi olan öğrencilerin \%51,3’ünün korunma yöntemi kullanmadığı bildirilmiştir. ${ }^{[3]}$

Aykan ve ark.'nın (2017) ${ }^{[15]}$ çalışmasında öğrencilerin çoğunluğunun $(\% 75,4)$ hangi hastalıkların cinsel yolla bulaştığını bildiği belirtilmiştir. Demir ve Şahin'in (2014) [20] çalışmasında en çok bilinen CYBH sırası ile; AIDS, sifiliz, gonore, hepatit B'dir. Elkinin (2015) ${ }^{[13]}$ çalışmasında en çok bilinen CYBH AIDS'tir. Akalpler ve ark.'nın $(2015)^{[3]}$ çalışmasında ise en merak edilen CYBH; AIDS, hepatit B ve gonoredir. Avcıkurt'un (2014), öğrencilerin AIDS konusunda bilgi düzeylerini araştıran çalışmasında öğrencilerin bilgi düzeylerinin yüksek olduğu bildirilmiştir. İncelenen çalışmaların sonuçlarına göre genelde en çok bilinen CYBH'nin AIDS olduğu gözlenmiştir. ${ }^{[18]}$

Çalışkan ve ark.'nın (2015) çalışmasında öğrencilerin CYBH konusunda korunma yollarını bildiği ancak tedavi ve komplikasyonlarına yönelik yeterli bilgiye sahip olmadığı bildirilmiştir. ${ }^{[4]}$ Avcıkurt'un (2014) çalışmasında öğrencilerin çoğu, bilgi düzeylerini yetersiz tanımlamasına rağmen bilgi düzeylerinin yeterli olduğu belirlenmiştir. ${ }^{[18]}$ Karasu ve ark.'nın (2017) çalışmasında hemşirelik bölümünde lisans eğitim alan 3. ve 4. sinıf öğrencilerinin, 1. ve 2. sınıf öğrencilerine göre bilgi düzeylerinin daha yüksek olduğu bildirilmiştir. ${ }^{[10]}$ Demir ve Şahin’in (2014) çalışmasında ise sağlık ile ilgili olan bölümlerin bilgi düzeyleri iyi iken, sağlık ile ilgili olmayan bölümdeki öğrencilerin bilgi düzeyleri yetersizdir. ${ }^{[20]}$ 
Tablo 1. İncelenen araştırmaların özellikleri

\begin{tabular}{|c|c|c|c|c|c|c|c|}
\hline Yazar/yıl & $\begin{array}{c}\text { Çalısmanın } \\
\text { amacı }\end{array}$ & $\begin{array}{c}\text { Çalışmanın } \\
\text { şekli }\end{array}$ & $\begin{array}{c}\text { Veri } \\
\text { toplama } \\
\text { araçları }\end{array}$ & Örneklem & $\begin{array}{l}\text { Temel } \\
\text { bulgular }\end{array}$ & Sonuç & $\begin{array}{l}\text { Kalite } \\
\text { Puanı }\end{array}$ \\
\hline $\begin{array}{l}\text { Avcıkurt, } \\
2014\end{array}$ & $\begin{array}{l}\text { Balıkesir Üniversitesi'nde } \\
\text { lisans eğitimi alan } \\
\text { öğrencilerinin, Mediko- } \\
\text { Sosyal sağılık birimine } \\
\text { başvuranların AIDS } \\
\text { konusunda bilgi } \\
\text { düzeyi ve tutumlarının } \\
\text { değerlendirilmesi } \\
\text { amaçlanmıştr. }\end{array}$ & Tanımlayıcı & $\begin{array}{l}\text { Anket } \\
\text { formu }\end{array}$ & $\begin{array}{l}\text { Mediko-Sosyal } \\
\text { sağlık birimine } \\
\text { başvuran toplam } \\
410 \text { öğrenci }\end{array}$ & 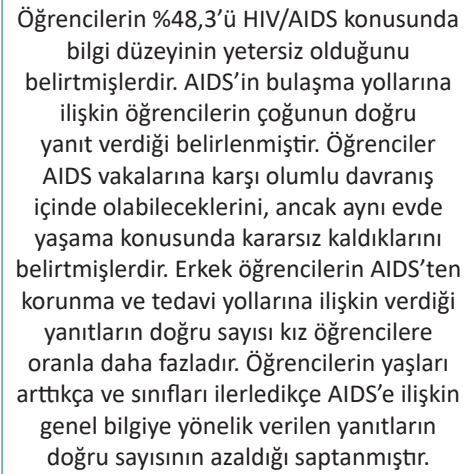 & $\begin{array}{c}\text { Öğrencilerin } \\
\text { çoğunluğu AIDS } \\
\text { konusunda bilgi } \\
\text { düzeylerini az olarak } \\
\text { tanımlasa da yeterli } \\
\text { bilgilerinin olduğu } \\
\text { ve AIDS'li olgulara } \\
\text { olumlu bir yaklaşım } \\
\text { sergiledikleri } \\
\text { belirlenmiştir. }\end{array}$ & Evet: 8 \\
\hline $\begin{array}{l}\text { Demir ve } \\
\text { Şahin, } 2014\end{array}$ & $\begin{array}{l}\text { Selçuk Üniversitesi'nde } \\
\text { lisans eğitimi alan } \\
\text { öğrencilerin CYBH } \\
\text { konusunda bilgi } \\
\text { düzeylerinin belirlenmesi } \\
\text { amaçlanmıştr. }\end{array}$ & Tanımlayıcı & $\begin{array}{l}\text { Anket } \\
\text { formu }\end{array}$ & 377 öğrenci & $\begin{array}{l}\text { Sağlıkla ilgili bölümde okuyan öğrenciler } \\
\text { CYBH konusunda kendini yeterli } \\
\text { hissetmekte (\%72,6), diğer bölümlerdeki } \\
\text { öğrenciler ise yetersiz hissetmektedir } \\
\text { (\%15,9). Kendini yetersiz hisseden } \\
\text { öğrencilerin oranı \%70,1 bulunmuştur. } \\
\text { AIDS en fazla bilinen CYBH'dir. Bunu, } \\
\text { sifiliz (\%20,3), hepatit (\%18,7) ve } \\
\text { gonoreyi (\%15,7) izlemiştir. En az bilinen } \\
\text { CYBH ise HPV, vajinit ve şankroid olarak } \\
\text { belirlenmiştir. }\end{array}$ & $\begin{array}{l}\text { Öğrencilerin } \\
\text { CYBH konusunda } \\
\text { genel olarak bilgi } \\
\text { düzeylerinin yetersiz } \\
\text { olduğu, ancak sağlık } \\
\text { alanında öğrenim } \\
\text { gören öğrencilerin, } \\
\text { diğer öğrencilere } \\
\text { göre bilgi düzeyleri } \\
\text { daha yüksek } \\
\text { bulunmuştur. }\end{array}$ & $\begin{array}{l}\text { Evet: } 5 \\
\text { Hayır: } 3\end{array}$ \\
\hline $\begin{array}{l}\text { Karataş ve } \\
\text { ark., } 2014\end{array}$ & \begin{tabular}{|} 
Trakya Üniversitesi \\
Tıp Fakültesi'nde öğrenim \\
gören öğrencilerin \\
CYBH konusunda bilgi \\
düzeylerinin belirlenmesi \\
ve komite eğitim sisteminin \\
etkisini saptamak \\
amaçlanmıştr.
\end{tabular} & Tanımlayıcı & $\begin{array}{l}\text { Anket } \\
\text { formu }\end{array}$ & 407 Tıp öğrencisi & $\begin{array}{l}\text { 3. ve 4. sınıftaki tıp öğrenimi alanların bilgi } \\
\text { düzeyi, } 1 \text {. ve } 2 \text {. sinfftakilere göre yüksek } \\
\text { bulunmuştur ve fark istatistiksel olarak } \\
\text { anlamlı bulunmuştur }(p=0,001) \text {. }\end{array}$ & $\begin{array}{l}\text { 1. ve } 2 \text {. sınıftaki } \\
\text { öğrencilerin bilgi } \\
\text { düzeyleri yetersiz } \\
\text { bulunmuştur. } \\
\text { Komite sistemiyle } \\
\text { verilen derslerin, } \\
\text { CYBH hakkında } \\
\text { öğrencilerin bilgi } \\
\text { düzeylerini bir } \\
\text { miktar arttğı } \\
\text { belirlenmiştir. }\end{array}$ & $\begin{array}{l}\text { Evet: } 5 \\
\text { Hayır: } 3\end{array}$ \\
\hline $\begin{array}{l}\text { Akalpler ve } \\
\text { Eroğlu, } 2015\end{array}$ & $\begin{array}{c}\text { KKTC Yakın Doğu } \\
\text { Üniversitesi'ndeki fakülte } \\
\text { ve yüksek okullardaki } \\
\text { ögrencilerin CYBH } \\
\text { konusunda bilgi düzeylerini } \\
\text { ve cinsel davranışlarını } \\
\text { saptamak amaçlanmıştır. }\end{array}$ & $\begin{array}{l}\text { Tanımlayıcı } \\
\text { ve kesitsel }\end{array}$ & $\begin{array}{l}\text { Anket } \\
\text { formu }\end{array}$ & 384 öğrenci & $\begin{array}{c}\text { Öğrencilerin } \% 40,1^{\prime} \text { 'inin CYBH'e yönelik } \\
\text { bilgi düzeyi "orta", } \% 36,5^{\prime} \text { 'inin yeterli ve } \\
\% 23,4^{\prime} \text { 'ünün yetersiz düzeyde olduğu } \\
\text { belirlenmiştir. Öğrencilerin neredeyse } \\
\text { tamamına yakını AIDS'in kan ve cinsel } \\
\text { bulaş yolu bilirken, yaklaşı üçte birinin } \\
\text { "anneden bebeğe doğum sırasında", } \\
\text { yarısının ise "ortak tuvalet" ve "sivrisinek" } \\
\text { yoluyla bulaşabildiğini belirttikleri } \\
\text { belirlenmiştir. }\end{array}$ & $\begin{array}{l}\text { Öğrencilerin } \\
\text { CYBH konusunda } \\
\text { bilgi seviyesi orta } \\
\text { düzeyde bulunmuş } \\
\text { ve bazıı riskli } \\
\text { cinsel davranışlar } \\
\text { sergiledikleri } \\
\text { saptanmıştr. }\end{array}$ & $\begin{array}{l}\text { Evet: } 5 \\
\text { Hayır: } 3\end{array}$ \\
\hline $\begin{array}{l}\text { Bakır ve } \\
\text { Kızılkaya } \\
\text { Beji, } 2015\end{array}$ & \begin{tabular}{|} 
Mehmet Akif Ersoy \\
Üniversitesi'nde bir \\
meslek yüksekokulunda \\
ve sağlık hizmetleri \\
meslek yüksekokulundaki \\
öğrencilerin CYBH konusu \\
hakkında bilgi düzeylerinin \\
ve bilgi düzeylerini \\
etkileyen faktörlerin \\
saptanması amacıyla \\
yapılmışır.
\end{tabular} & Tanımlayıcı & $\begin{array}{l}\text { Kişisel bilgi } \\
\text { formu (KFB) } \\
\text { ve CYBH } \\
\text { bilgi testi }\end{array}$ & \begin{tabular}{|}
261 meslek \\
yüksekokulu \\
öğrencisi ve 256 \\
sağlık hizmetleri \\
meslek \\
yüksekokulu \\
(256) öğrencisi \\
olmak üzere \\
toplam 517 \\
öğrenci
\end{tabular} & $\begin{array}{l}\text { Öğrencilerin \% } 39,1^{\prime} \text { inin en az bir kez cinsel } \\
\text { birliktelik deneyimi olduğu belirlenmiş ve } \\
\text { bu öğrencilerin } \% 61,8^{\prime} \text { i cinsel birleşme } \\
\text { esnasında korunma yöntemi kullandığını } \\
\text { belirtmiştir. Erkek öğrencilerin ve cinsel } \\
\text { birliktelik deneyimi olan öğrencilerin, CYBH } \\
\text { Bilgi Testi doğru cevap ortalamalarının } \\
\text { daha yüksek olduğu belirlenmiştir. Kadın } \\
\text { ögrencilerin erkek öğrencilere göre; cinsel } \\
\text { beraberlik tecrübesi olmayan öğrencilerin } \\
\text { tecrübesi olanlara göre CYBH Bilgi Testi } \\
\text { doğru cevap ortalamalarının daha düsük } \\
\text { olduğu belirlenmiş, ancak fark istatistiksel } \\
\text { olarak anlamsız bulunmuştur }(p>0,05) \text {. }\end{array}$ & $\begin{array}{l}\text { Öğrencilerin CYBH } \\
\text { konusunda orta } \\
\text { düzeyde bilgi } \\
\text { sahibi olduğu, } \\
\text { bilmediklerinin, } \\
\text { yanlış bildiklerinden } \\
\text { daha çok olduğu } \\
\text { ortaya konmuştur. }\end{array}$ & Evet: 8 \\
\hline $\begin{array}{l}\text { Çalışkan ve } \\
\text { ark., } 2015\end{array}$ & \begin{tabular}{|l} 
Balıkesir Üniversitesi'ndeki \\
rehberlik bölümü \\
öğrencilerinin CYBH \\
konusu hakkında bilgi \\
düzeylerini belirlemek \\
ve sosyodemografik \\
özelliklerin bilgi \\
düzeylerine etkisinin olup \\
olmadığını saptamak \\
amacıyla yapılmıştr.
\end{tabular} & Kesitsel & $\begin{array}{l}\text { KFB ve } \\
\text { CYBH bilgi } \\
\text { testi }\end{array}$ & \begin{tabular}{|c|} 
Turizm fakültesi \\
rehberlik bölümü \\
öğrencileri; \\
toplam 130 \\
öğrenci.
\end{tabular} & $\begin{array}{c}\text { Araştrrma grubunun } \% 78,5^{\prime} \text { i } \mathrm{CYBH} \\
\text { konusunda bilgi almısı̧tr. Araş̧trmada } \\
\text { CYBH bilgi testinin doğru cevap ortalaması } \\
24,96 \pm 4,54^{\prime} \text { tür. Erkek öğrencilerde ve yaz } \\
\text { stajinı yapmışöğrencilerde CYBH bilgi testi } \\
\text { puan ortalaması daha yüksek bulunmuştur } \\
(p<0,05) .\end{array}$ & $\begin{array}{l}\text { Öğrenciler CYBH'den } \\
\text { korunma yollarını } \\
\text { bilmesine karşın } \\
\text { bu hastalıkların } \\
\text { komplikasyonları } \\
\text { ve tedavisi ile ilgili } \\
\text { bilgi düzeylerinin } \\
\text { yeterli olmadığı } \\
\text { saptanmıştr. }\end{array}$ & $\begin{array}{l}\text { Evet: } 6 \\
\text { Hayır: } 2\end{array}$ \\
\hline
\end{tabular}


Tablo 1 devamı. İncelenen araştırmaların özellikleri

\begin{tabular}{|c|c|c|c|c|c|c|c|}
\hline Yazar/yıl & $\begin{array}{l}\text { Çalışmanın } \\
\text { amacı }\end{array}$ & $\begin{array}{l}\text { Çalışmanın } \\
\text { şekli }\end{array}$ & $\begin{array}{l}\text { Veri } \\
\text { toplama } \\
\text { araçları }\end{array}$ & Örneklem & $\begin{array}{l}\text { Temel } \\
\text { bulgular }\end{array}$ & Sonuç & $\begin{array}{l}\text { Kalite } \\
\text { Puanı }\end{array}$ \\
\hline Elkin, 2015 & $\begin{array}{l}\text { Mersin Üniversitesi } \\
\text { Sağlık Bilimleri } \\
\text { Yüksekokulu'ndaki } \\
\text { öğrencilerin CYBH } \\
\text { konusu hakkında } \\
\text { bilgi düzeyleri ve bilgi } \\
\text { düzeyini etkileyen } \\
\text { faktörleri belirlemek } \\
\text { amacıyla yapılmıştır. }\end{array}$ & Kesitsel & $\begin{array}{l}\text { Anket } \\
\text { formu }\end{array}$ & $\begin{array}{l}\text { Sağlık Bilimleri } \\
\text { Yüksekokulundaki } \\
\text { toplam } 552 \\
\text { öğrenci. }\end{array}$ & $\begin{array}{l}\text { Öğrencilerin } \% 57,4 \text { 'ü CYBH hakkında } \\
\text { kendisini yetersiz bulduğunu, \%72,1'i } \\
\text { CYBH'nin tedavi edilebileceğini } \\
\text { düşündüklerini bildirmiştir. }\end{array}$ & $\begin{array}{l}\text { Öğrencilerin } \\
\text { CYBH hakkında } \\
\text { bilgilerinin } \\
\text { yetersiz olduğu ve } \\
\text { bu konuda bilgi } \\
\text { almak istedikleri } \\
\text { saptanmıştir. }\end{array}$ & $\begin{array}{l}\text { Evet: } 7 \\
\text { Hayır: } 1\end{array}$ \\
\hline $\begin{array}{l}\text { Vural ve } \\
\text { ark., } 2015\end{array}$ & $\begin{array}{l}\text { Sağlık Meslek } \\
\text { Yüksekokulu } \\
\text { öğrencilerinin CYBH ile } \\
\text { ilgili bilgi düzeylerinin } \\
\text { ve sosyo-demografik } \\
\text { özelliklerin bilgilerine } \\
\text { etkisinin saptanması } \\
\text { amaçlamıştır. }\end{array}$ & Tanımlayıcı & $\begin{array}{l}\text { KFB ve } \\
\text { CYBH bilgi } \\
\text { testi }\end{array}$ & $\begin{array}{c}\text { Toplam } 240 \\
\text { öğrenci }\end{array}$ & 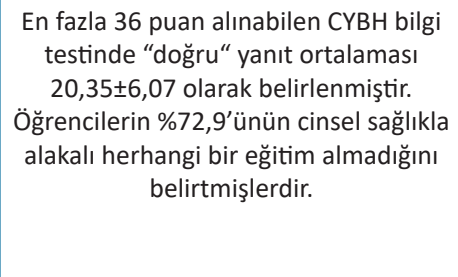 & $\begin{array}{l}\text { Öğrencilerinin } \\
\text { CYBH konusunda } \\
\text { orta düzeyde } \\
\text { bilgilerinin olduğu } \\
\text { saptanmıştir. }\end{array}$ & Evet: 8 \\
\hline $\begin{array}{l}\text { Akça ve } \\
\text { ark., } 2016\end{array}$ & $\begin{array}{l}\text { Anket formu ve } \mathrm{CYBH} \\
\text { bilgi testi }\end{array}$ & $\begin{array}{l}\text { Tanımlayıcı } \\
\text { ve kesitsel }\end{array}$ & & $\begin{array}{l}\text { Tıp fakültesi } \\
\text { 3. dönem } \\
\text { öğrencileri; } \\
\text { toplam } 104 \\
\text { öğrenci. }\end{array}$ & $\begin{array}{c}\text { Öğrencilerin } \% 22,1^{\prime} \text { inin CYBH risk } \\
\text { faktörlerinin tamamına doğru yanıt } \\
\text { verdiği saptandı. }\end{array}$ & $\begin{array}{l}\text { Öğrencilerin } \\
\text { CYBH'ın bazı } \\
\text { konularında bilgi } \\
\text { düzeyi düşük } \\
\text { olduğu, CYBH ve } \\
\text { korunma yolları } \\
\text { hakkında bilgi } \\
\text { almak istedikleri } \\
\text { belirlenmiştir. }\end{array}$ & $\begin{array}{l}\text { Evet: } 6 \\
\text { Hayır: } 2\end{array}$ \\
\hline $\begin{array}{l}\text { Karasu ve } \\
\text { ark., } 2017\end{array}$ & $\begin{array}{l}\text { Güneydoğu Anadolu } \\
\text { bölgesindeki bir } \\
\text { Üniversite'de, hemşirelik } \\
\text { öğrencilerinin } \\
\text { CYBH konusunda } \\
\text { bilgi düzeylerinin } \\
\text { belirlenmesi } \\
\text { amaçlanmıştır. }\end{array}$ & Kesitsel & $\begin{array}{l}\text { KFB ve } \\
\text { CYBH bilgi } \\
\text { testi }\end{array}$ & $\begin{array}{l}\text { Hemşirelik } \\
\text { öğrencileri; } \\
\text { toplam } 301 \\
\text { öğrenci. }\end{array}$ & $\begin{array}{c}\text { Öğrencilerin CYBH bilgi testine } \\
\text { göre doğru yanıt puan ortalaması } \\
26,12 \pm 5,85 \text { ve yanlış yanıt ortalamaları } \\
4,37 \pm 3,88 \text { bulunmuştur. Yaş arttkça } \\
\text { öğrencilerin bilgi düzeyi artmakta ve } \\
\text { cinsel konuları ebeveynleriyle paylaşan } \\
\text { öğrencilerin bilgi düzeyleri daha yüksek } \\
\text { belirlenmiştir. }\end{array}$ & $\begin{array}{l}\text { Öğrencilerin } \\
\text { genel olarak } \\
\text { CYBH hakkında } \\
\text { bilgi düzeylerinin } \\
\text { iyi olduğu } \\
\text { belirlenmiştir. }\end{array}$ & $\begin{array}{l}\text { Evet: } 4 \\
\text { Hayır: } 4\end{array}$ \\
\hline $\begin{array}{l}\text { Turan ve } \\
\text { Erdoğan, } \\
2017\end{array}$ & $\begin{array}{l}\text { Pamukkale Üniversitesi } \\
\text { Sağlık Yüksekokulu'ndaki } \\
\text { hemşirelik bölümü } \\
\text { öğrencilerinin CYBH } \\
\text { hakkında bilgi düzeyi } \\
\text { ve görüşlerinin } \\
\text { belirlenmesi } \\
\text { amaçlanmıştır. }\end{array}$ & $\begin{array}{c}\text { Kesitsel/ } \\
\text { Tanımlayıcı }\end{array}$ & $\begin{array}{l}\text { Anket } \\
\text { formu }\end{array}$ & $\begin{array}{l}481 \text { hemşirelik } \\
\text { öğrencisi }\end{array}$ & $\begin{array}{c}\text { Öğrencilerin \%60,5'inin CYBH } \\
\text { konusunda bilgisinin iyi düzeyde } \\
\text { olduğu, \%44,1'inin bilgi edinme } \\
\text { gereksinimi olduğunu belirtmişlerdir. } \\
\text { Öğrencilerin \%24,1'i CYBH'nin cinsel } \\
\text { beraberlik harici başka bir yolla } \\
\text { bulaşmadığını belirtmiş, \%19,5'i CYBH } \\
\text { ile alakalı şüpheleri olursa rahatça } \\
\text { sağlık kuruluşuna başvuramayacaklarını } \\
\text { belirtmişlerdir. Öğrencilerin sınıfları } \\
\text { yükseldikçe CYBH hakkında bilgi } \\
\text { düzeylerinin arttı̆ı belirlenmiştir. }\end{array}$ & $\begin{array}{l}\text { Öğrencilerin } \\
\text { CYBH konusunda } \\
\text { bilgi düzeylerinin } \\
\text { yetersiz olduğu } \\
\text { belirlenmiştir. }\end{array}$ & $\begin{array}{l}\text { Evet: } 7 \\
\text { Hayır: } 1\end{array}$ \\
\hline $\begin{array}{l}\text { Babaoğlu ve } \\
\text { ark., } 2018\end{array}$ & $\begin{array}{l}\text { Ahi Evran Üniversitesi, } \\
\text { Sağlık Yüksekokulu'ndaki } \\
\text { hemşirelik bölümü } \\
\text { öğrencilerinin HIV/ } \\
\text { AIDS konusunda } \\
\text { bilgi düzeylerini } \\
\text { ve tutumlarının } \\
\text { belirlenmesi } \\
\text { amaçlanmıştır. }\end{array}$ & Tanımlayıcı & $\begin{array}{l}\text { Anket } \\
\text { formu }\end{array}$ & $\begin{array}{l}351 \text { hemşirelik } \\
\text { öğrencisi }\end{array}$ & $\begin{array}{c}\text { Öğrencilerin } \% 65 \text { 'i AIDS hastası olan } \\
\text { kişilerden uzak duracağını, \%17,9'u } \\
\text { AIDS hastalarının toplumdan uzak } \\
\text { tutulması kanaatinde olduklarını } \\
\text { bildirmiştir. Öğrencilerin \%83,2'si } \\
\text { meslek yönünden AIDS'li hastaların } \\
\text { riskli olduklarını düşündüklerini } \\
\text { bildirmiştir. Öğrencilerin yaşları ve } \\
\text { bulundukları sınıfla AIDS bilgi düzeyi } \\
\text { puan ortalaması arasındaki fark anlamlı } \\
\text { bulunmuştur ( } p<0,05 \text { ). Öğrencilerin } \\
\text { AIDS'li olduğunu bildiği kişiden } \\
\text { uzak durma, evlenecek olan kişilere } \\
\text { evlenmeden önce test istemi ile AIDS } \\
\text { bilgi düzeyi puan ortalaması arasındaki } \\
\text { fark anlamlı bulunmuştur ( } p<0,05 \text { ). }\end{array}$ & $\begin{array}{l}\text { Öğrencilerin HIV/ } \\
\text { AIDS konusunda } \\
\text { bilgi düzeylerinin } \\
\text { yetersiz olduğu, } \\
\text { yanlış tutum } \\
\text { ve davranış } \\
\text { sergiledikleri } \\
\text { saptanmıştır. }\end{array}$ & $\begin{array}{l}\text { Evet: } 6 \\
\text { Hayır: } 2\end{array}$ \\
\hline
\end{tabular}


Karataş ve ark.'nın (2014) çalışmasında 1. ve 2. sınıf tıp fakültesi öğrencilerinin $\mathrm{CYBH}$ konusunda bilgi düzeyleri yetersiz iken, 3. ve 4. sınıf öğrencilerinin yeterli bilgi düzeyine sahip olduğu ${ }^{[21]}$; dört çalışmada ${ }^{[3,12,16,18]}$ bilgi düzeylerinin orta düzeyde olduğu, Karasu ve ark. (2017) [10] çalışmasında bilgi düzeylerinin yeterli olduğu bildirilmiştir. Diğer 7 çalışmada ise öğrencilerin $\mathrm{CYBH}$ konusunda yetersiz bilgi düzeyine sahip olduğu belirlenmiştir. $[4,10,11,13,14,16,20]$ İncelenen makalelerin veri analizi Tablo 1'de verilmiştir.

\section{TARTIȘMA}

Üniversite öğrencilerinin bağımsızlık duygusunun artması, aile kontrolünün azalması, erken yaşlarda cinsel deneyim kazanması, damar içi madde kullanımı ve dövmenin giderek yaygınlaşmasına bağlı Human Immunodeficiency Virus (HIV)/AIDS, Hepatit B ve Hepatit C gibi bulaşıcı hastalıklara yakalanma riski de artış göstermektedir. ${ }^{[22,23]}$ CYBH'nin görülme döneminin cinsel işlevle ilişkili olduğu belirtilmektedir. Bu dönemde bulaşın artmasına, gençlerin yeterince doğru bilgi sahibi olmamasının neden olduğu belirtilmektedir. ${ }^{[7]}$

$\mathrm{Bu}$ sistematik derlemeye alınan çalışmaların sonuçlarına göre, CYBH bilgi testine göre doğru cevap puan or-

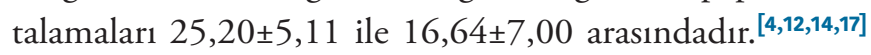

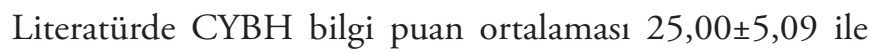
$11,60 \pm 8,78$ arasında bildirilmiştir. ${ }^{[19,24,25]} \mathrm{CYBH}$ bilgi testinden alınabilecek en yüksek puan 36 iken, bu sonuçlar bilgi düzeyinin orta ya da düşük düzeyde olduğunu göstermektedir. Yapılan çalışmalarda üniversite öğrencilerinin CYBH konusunda bilgi düzeylerinin yeterli olmadığı bildirilmiştir. ${ }^{[25-38]}$ İncelediğimiz çalışmalardan 6'sında öğrencilerin CYBH bilgi düzeyinin yetersiz olduğu ${ }^{[4,11,13,14,16,20,21]}$, dört çalışmanın sonucuna göre orta düzeyde olduğu belirlenmiştir. ${ }^{[3,12,16,18]}$ Ayrıca, sistematik derlemeye alınan çalışmaların bulgularına göre, sağlıkla ilgili alanlarda lisans eğitimi alan öğrencilerin, sağlık dişı alanlarda öğrenim gören öğrencilere oranla bilgi seviyelerinin daha iyi olduğu belirtilmektedir. ${ }^{[12,20,21]}$ Ayrıca sağlık alanında öğrenim gören öğrencilerde, sınıf düzeyi yükseldikçe bilgi düzeyinin anlamlı derecede arttığı bildirilmektedir. ${ }^{\text {[2-30] }}$ Bu durumun sağlık ile ilgili okullarda öğrenim gören öğrencilerin $\mathrm{CYBH}$ konusunda eğitim alması ile ilgili olduğu düşünülmektedir.

İncelediğimiz çalışmalardan Akalpler ve Eroğlu'nun (2015) çalışmasında öğrencilerin yaklaşık üçte birinin "anneden bebeğe doğum sırasında", yarısının ise "ortak tuvalet" ve "sivrisinek" yoluyla CYBH'ın bulaşabildiğini belirttikleri belirlenmiştir. ${ }^{[3]}$ Karasu ve ark.'nın (2017) çalışmasında öğrencilerin \%26,8'inin HIV'li kişiler ile çatal, tabak, bardak paylaşılmasıyla AIDS’in bulaşabileceğini düşündükleri belirtilmiştir. ${ }^{[10]}$ Avcıkurt'un (2014) çalışmasında öğrencilerin bazıları HIV'in sivrisineklerden bulaştığını, AIDS'li kişilerden kaçınmak ile HIV'den korunabileceğini, HIV'e karşı etkili bir aşının olduğunu bildikleri belirtilmiştir. ${ }^{[18]}$ Vural ve ark.'nın (2015) çalışmasında da öğrencilerin çoğunluğunun bulaş yoluna ilişkin yanlış bilgiye sahip oldukları ya da bilgi sahibi olmadıkları belirtilmiştir. Akalpler ve Eroğlu'nun (2015) çalışmasında öğrencilerin \%71,5'inin AIDS'in, doğum sırasında anneden bebeğe geçtiğini bilmediği, ayrıca öğrencilerin yarısının ortak tuvalet kullanımı, tokalaşma, sivrisinek ısırması ile AIDS'in bulaşabildiğini belirttikleri bildirilmiştir. ${ }^{[16]}$ Yapılan başka çalışmalarda da öğrencilerin CYBH'den korunma yollar1 genel olarak bilinirken (en çok kondom, sonra tek eşlilik); belirti, bulaş yolu ve tedavi konusunda bilgilerinin yetersiz olduğu bildirilmiştir. ${ }^{[6,29,30]}$ Ayrıca Folasayo ve ark.'nın (2017) çalışmasında, şaşırtıcı bir şekilde tüberküloz ve astımın da öğrencilerin birçoğu tarafından $\mathrm{CYBH}$ olarak bilindiği bildirilmiştir. ${ }^{[28]}$ Yazganoğlu ve ark.'nın (2012) çalışmasında öğrencilerin \%11,6’sı derin öpüşme ile, \%1,1'i sarılma ile CYBH'nin bulaşabileceğini bildirmiştir. ${ }^{[31]}$ Yaşar ve ark.'nın (2019) çalışmasında da öğrencilerin \%90' ${ }_{1}$ CYBH'nin öpüşme yoluyla bulaşabildiğini bildirmiştir. ${ }^{[32]}$ Pınar ve ark.'nın (2009) araştırmasında ise öğrencilerin \%76,2'sinin CYBH belirtilerini bilmediği belirtilmiştir. ${ }^{[33]} \mathrm{Bu}$ sonuçlara göre, CYBH'nin bulaşma yolları ve belirtilerini yanlış bilen kişi sayısı az gibi görünse de, bu temel bilgilerin düzeltilmesi önem arz etmektedir. Öğrencilerin doğru bilgiye ulaşmaları için eğitime gereksinim duydukları sonucuna varılabilir.

İncelediğimiz makalelerden birinin bulgularına göre, öğrencilerin bazılarının cinsel ilişki deneyimi olduğu ve cinsel deneyimi olanların CYBH konusunda bilgi düzeyinin anlamlı derecede daha iyi düzeyde olduğu belirlenmiştir. [12] Yapılan başka çalışmalarda da cinsel deneyimi olan öğrencilerin $\mathrm{CYBH}$ konusunda bilgi düzeylerinin daha yüksek olduğu bildirilmiştir. ${ }^{\left[{ }^{[9,25]}\right.}$ Ancak, incelediğimiz çalışmalarda cinsel deneyimi olan öğrencilerin çoğunun korunmak için bir yöntem kullanmadığı belirlenmiştir. ${ }^{[3,12]}$ Literatürde de cinsel deneyimi olan öğrencilerin çoğunluğunun bir korunma yöntemi kullanmadığı ve öğrencilerin birçoğunun da birden fazla cinsel partneri olduğu bildirilmiştir. ${ }^{[3,24,28]}$ Cinsel ilişkide herhangi bir korunma yöntemi kullanmayan öğrencilerin CYBH bulaş yolları konusunda bilgi düzeyinin yeterli olmadığı sonucuna ulaşılabilir. Bu bağlamda CYBH'den korunma yolları ve bulaş yolları konusunda bilgi eksikliği için öğrencilerin detaylı eğitime ihtiyaçları olduğunu düşünüyoruz. 
Sistematik derlemeye alınan çalışmaların sonuçlarına göre en çok bilinen CYBH, AIDS olarak belirlenmiş, bunu gonore, sifiliz ve hepatit takip etmiştir. ${ }^{[13,20]}$ Daha önce yapılan çalışmaların sonucu bu sistematik incelemedeki çalışmaların bulgularına benzerdir. ${ }^{[25,27,31,34-37]} \mathrm{Bu}$ durum, AIDS ile ilgili televizyon filmlerinin ya da sosyal medyada AIDS konusunda paylaşımların fazla olmasından kaynaklanıyor olabilir. Nitekim incelediğimiz çalışmalarda görüldüğ̈̈ gibi; $\mathrm{CYBH}$ konusunda daha önceden bilgi alan öğrencilerin, bilgiye en çok internet ve televizyon gibi iletişim kitle araçlarından ulaşı ı̆ı belirlenmiştir. ${ }^{[3,10,14,18]}$ Bununla birlikte Karabulutlu ve Kılıç'ın (2011) çalışmasında öğrencilerin \%47,6'sı dergi ve kitaplardan, \%42,4'ü medyadan bilgi almışır. ${ }^{[38]}$ Yazganoğlu ve ark.'nın (2012) çalışmasında öğrencilerin bilgi kaynağının en çok $(\% 63,9)$ internet olduğu, bunu \%48 ile sağlık personeli takip ettiği bildirilmiştir. ${ }^{[31]}$ Bazı çalışmalarda CYBH konusunda sağlık personelinden bilgi alma oranı \%7,4 ile \%2,4 arasında bildirilmiştir. ${ }^{[6,32,36,38]}$ Böyle önemli bir konunun en güvenilir bilgi kaynağı sağlık profesyonelleri iken öğrencilerin genel olarak iletişim kitle araçlarını tercih etmeleri dikkat çekicidir. Bu sonuç ise öğrencilerin iletişim kitle araçlarından edindikleri yanlış ya da eksik bilgilerini düzeltmek için okullarda profesyoneller tarafından bilinçlendirilmesi gerektiği sonucunu doğurabilir.

\section{SONUÇ Ve ÖNERILER}

İncelenen çalışmalar sonucunda üniversite öğrencilerinin CYBH konusunda yeterli bilgi düzeyine sahip olmadığı görülmüştür. Öğrencilerin birçoğunun cinsel deneyimleri sırasında herhangi bir yöntem ile korunmadığı belirlenmiştir. CYBH konusunda en güvenilir bilgiye sağlı profesyonellerinden ulaşılması gerekirken, öğrencilerin iletişim kitle araçlarından bilgi edindiği dikkati çekmektedir. Yetersiz bilgi düzeyine sahip öğrenciler CYBH'ye ilişkin risk altındadır. Bu nedenlerle, öğrencilerin doğru bilgilere ulaşması için sağlık dışı okullarda alanında uzmanlaşmış hemşireler tarafından kapsamlı eğitim programları ya da konferanslar düzenlenmesi, ayrıca konu ile ilgili resimli bilgi kitapçığı hazırlanarak öğrencilere dağıtılması önerilir.

\footnotetext{
Hakem Değerlendirmesi

Dış bağımsız.

Çıkar Çatışması

Yazarlar çıkar ilişkisi olmadığını beyan etmişlerdir.

\section{Finansal Destek}

Herhangi bir mali destek alınmamıştır.
}

\section{Peer-review}

Externally peer-reviewed.

Conflict of Interest

No conflict of interest was declared by the authors.

Financial Disclosure

No financial support has been received.

\section{KAYNAKLAR}

1. WHO. WHO Media Centre. Sexual and reproductive health [Updated: November 2019; Cited: 2014 May 8]. http://www.who. int/topics/sexually_transmitted_infections/en/

2. Ravi RP, Kulasekaran RA. Comprehensive knowledge and practices about sexually transmitted infections among young married rural women in South India. Am J Epidemiol Infect Dis 2014;2:41-6. [CrossRef]

3. Akalpler Ö, Eroğlu K. Kuzey Kıbrıs Türk Cumhuriyeti'nde üniversite öğrencilerinin sık görülen cinsel yolla bulaşan enfeksiyonlara ilişkin bilgileri ve cinsel davranışları. Hacettepe Üniversitesi Hemşirelik Fakültesi Derg 2015;2:1-19. https:// dergipark.org.tr/tr/download/article-file/88660

4. Çalışkan T, Çevik C, Ergün S. Üniversite öğrencilerinin cinsel yolla bulaşan hastalıklar konusundaki bilgi düzeylerinin değerlendirilmesi. Balıkesir Sağlık Bilimleri Derg 2015;4:2731. https://www.journalagent.com/bsbd/pdfs/BSBD-67699RESEARCH_ARTICLE-CALISKAN.pdf

5. Koluaçık S, Güneş G, Pehlivan E. İnönü üniversitesi öğrencilerinin üreme sağlığı konularında bilgi düzeyleri ve hizmetten beklentileri. İnönü Üniversitesi Tip Fakültesi Derg 2010;17:7-14. https:// dergipark.org.tr/tr/download/article-file/139346

6. Özalp S, Tanır HM, Ilgın H, KarataşA, Ilgın B. Eskişehir Osmangazi Üniversitesi Tip ve Mühendislik Fakültesi öğrencilerinin cinsel yolla bulaşan hastalıklar ve aile planlaması konusundaki bilgi ve tutumlarının değerlendirilmesi. Düzce Tıp Derg 2012;14:18-21. https://dergipark.org.tr/tr/download/article-file/793602

7. Karaköse A, Aydın S. Genç erkeklerin cinsel yolla bulaşan hastalıklar hakkındaki bilgi düzeyinin incelenmesi. Yeni Üroloji Derg 2011;6:31-7. https://dergipark.org.tr/tr/download/articlefile/1015239

8. Karaçam Z. Sistematik derleme metodolojisi: sistematik derleme hazırlamak için bir rehber. DEUHYO ED 2013;6:26-33. https:// dergipark.org.tr/tr/download/article-file/753523

9. Joanna Briggs Institute [Internet]. Critical Appraisal Tools; 2018. https://jbi.global/critical-appraisal-tools

10. Karasu F, Göllüce A, Güvenç E, Dadük, S, Tuncel T. Hemşirelik öğrencilerinin cinsel yolla bulaşan hastalıklar hakkındaki bilgilerinin incelenmesi. İnönü Üniversitesi Sağlık Hizmetleri Meslek Yüksek Okulu Derg 2017;5:1-15. https://dergipark.org.tr/ tr/download/article-file/449405

11. Babaoğlu ÜT, Demir G, Biçer S. Hemşirelik bölümü öğrencilerinin HIV/AIDS hakkındaki bilgi düzeyleri ve tutumlarının değerlendirilmesi. Bozok Tip Derg 2018;8:18-24. https:// dergipark.org.tr/tr/download/article-file/444885

12. Bakır N, Kızılkaya Beji N. Öğrencilerinin Cinsel Yolla Bulaşan Hastalıklar Konusundaki Bilgi Düzeyleri. Düzce Üniversitesi Sağlık Bilimleri Enstitüsü Derg 2013;5:10-6. https://dergipark. org.tr/tr/download/article-file/56605

13. Elkin N. Üniversite Öğrencilerinin Cinsel Yolla Bulaşan Hastalıklar Konusunda Bilgilerinin Araştırılması. Mersin Üniversitesi Sağlık Bilimleri Derg 2015;8:1-14. https://dergipark.org.tr/tr/download/ article-file/ 182793

14. Akça B, Altınay ZÖ, Demirbaşoğlu H, Kırdar İ, Okol B, Özkan HG, et al. Bir tıp fakültesinde dönem III öğrencilerinin cinsel yolla bulaşan hastalıklar ve korunma yöntemleri hakkındaki bilgi ve tutumları. Family Pract Palliat Care 2016;1:48-52. http://www. fppc.com.tr/tr/download/article-file/223070

15. Aykan ŞB, Altındiş M, Ekerbiçer H, Aslan FG, Altındiş S. Üniversite öğrencilerinin sosyal medya kullanımı ve cinsel yolla bulaşan hastalıklarla ilgili farkındalıkları. Kocaeli Üniversitesi Sağllk Bilimleri Derg 2017;3:1-5. https://dergipark.org.tr/tr/ download/article-file/372696 
16. Irmak Vural P, Bakır N, Oskay Ü. Meslek Yüksekokulu öğrencilerinin cinsel yolla bulaşan enfeksiyonlar konusundaki bilgi düzeyleri. KASHED 2015;2:58-70. https://dergipark.org.tr/tr/ download/article-file/207480

17. Turan T, Erdoğan Ç. Hemşirelik Öğrencilerinin Cinsel Yolla Bulaşan Enfeksiyonlar Konusundaki Bilgi Düzeyleri ve Görüşleri. JAREN 2017;3:129-36. https://jag.journalagent.com/jaren/pdfs/ JAREN_3_3_129_136.pdf

18. Avcıkurt AS. Balıkesir üniversitesi öğrencilerinin hıv/aıds hakkındaki bilgi düzeyi ve tutumlarının değerlendirilmesi. Balıkesir Sağlık Bilimleri Derg 2014;3:79-86. [CrossRef]

19. Siyez, DM, Siyez E. Üniversite öğrencilerinin cinsel yolla bulaşan hastalıklara ilişkin bilgi düzeylerinin incelenmesi. Türk Üroloji Derg 2009;35:49-55. https://www.turkishjournalofurology.com/ content/files/sayilar/18/buyuk/49-55.pdf

20. Demir G, Şahin TK. Selçuk üniversitesi öğrencilerinin cinsel yolla bulaşan hastalıklar konusundaki bilgi düzeylerinin belirlenmesi. Düzce Üniversitesi Sağlık Bilimleri Enstitüsü Derg 2014;4:19-24. https://dergipark.org.tr/tr/download/article-file/56576

21. Karataş N, Boncukçu E, Demirkıran H, Küçükyörük E, Kaymak G, Kuloğlu F. Knowledge level of Trakya University medical school students about sexually transmitted diseases. Turk Med Student J 2014;1:61-4. https://dergipark.org.tr/tr/download/articlefile/404611

22. Savaşer S, Balcı S, Ceylan N, Yalçın ZH, Direk M, Balcı F, Bardak N. Lise Öğrencilerinin Hepatit B Hastalığı ve Hastalıktan Korunmaya Yönelik Farkındalık Durumu. İ. Ü. F. N. Hem Derg 2011;19:18. https://app.trdizin.gov.tr/makale/TVRRek56Y3dNQT09/ lise-ogrencilerinin-hepatit-b-hastaligi-ve-hastaliktan-korunmayayonelik-farkindalik-durumu

23. Kırmızıtoprak E, Şimşek Z. Cinsel Yolla Bulaşan Hastalıklar ve Güvenli Cinsel Yaşam Konusunda Gençlerin Bilgi ve Davranışlarına Akran Eğitiminin Etkisi. TAF Prev Med Bull 2011;10:463-72. https://app.trdizin.gov.tr/makale/TWpNd01UWXhNUT09/ cinsel-yolla-bulasan-hastaliklar-ve-guvenli-cinsel-yasam-konusundagenclerin-bilgi-ve-davranislarina-akran-egitiminin-etkisi

24. Kara Ulu N, Demir H, Taşar MA, Dallar YB. Ankara’da düşük sosyoekonomik düzeyi olan bir bölgede ergenlerin cinsel yolla bulaşan hastalıklar hakkındaki bilgi düzeyleri. Türkiye Çocuk Hastalıkları Derg 2014;9:32-8. [CrossRef]

25. Anwar M, Sulaiman SAS, Ahmadi K, Khan TM. Awareness of school students on sexually transmitted infections (STIs) and their sexual behavior. a cross-sectional study conducted in Pulau Pinang, Malaysia. BMC Public Health 2010;10:47. [CrossRef]

26. Gao X, Wu Y, Zhang Y, Zhang N, Tang J, Qiu J, Lin X, Du Y. Effectiveness of school-based education on HIV/AIDS knowledge, attitude, and behavior among secondary school students in Wuhan, China. PLoS One 2012;7:e44881. [CrossRef]

27. Oppong-Asante K, Oti-Boadi M. HIV/AIDS knowledge among undergraduate university students: implications for health education programs in Ghana. Afr Health Sci 2013;13:270-7. [CrossRef]
28. Folasayo AT, Oluwasegun AJ, Samsudin S, Saudi SNS, Osman M, Hamat RA. assessing the knowledge level, attitudes, risky behaviors and preventive practices on sexually transmitted diseases among university students as future healthcare providers in the central zone of Malaysia: a cross-sectional study. Int J Environ Res Public Health 2017;14:159. [CrossRef]

29. Villanueva S, Mosteiro-Miguéns DG, Domínguez-Martís EM, López-Ares D, Novío S. Knowledge, Attitudes, and Intentions towards Human Papillomavirus Vaccination among Nursing Students in Spain. Int J Environ Res Public Health 2019;16:4507. [CrossRef]

30. Ünsar S, Yacan L, Yücel İ. Üniversite Öğrencilerinin HIV/ AIDS, Hepatit B, Hepatit C Enfeksiyon Hastalıkları Hakkındaki Farkındalık Düzeyleri. GÜSBD 2019;8:250-5. https://dergipark. org.tr/tr/download/article-file/820523

31. Yazganoğlu KD, Özarmağan G, Tozeren A, Özgülnar N. Üniversite öğrencilerinin cinsel yolla bulaşan infeksiyonlar hakkında bilgi, tutum ve davranışları. TÜRKDERM 2012;46:20-5. [CrossRef]

32. Yaşar Ö, Dikoğlu Buluş M, Özeser Kaymak G, Er Güneri S. Üniversite Öğrencilerinin Cinsel Yolla Bulaşan Hastalıklar Konusunda Bilgi ve Görüşlerinin İncelenmesi. JAREN 2019;5:538. [CrossRef]

33. Pınar G, Doğan N, Ökdem FŞ, Algıer L, Öksüz ME. Özel bir üniversitede okuyan öğrencilerin cinsel sağlıkla ilgili bilgi tutum ve davranışları. Tip Araştırmaları Derg 2009;7:105-13. https:// app.trdizin.gov.tr/makale/TVRBME9USTNOdz09/ozel-biruniversitede-okuyan-ogrencilerin-cinsel-saglikla-ilgili-bilgi-tutumve-davranislari-

34. Kanma-Okafor OJ, Onwuasoanya EE, Sekoni AO, Ayankogbe OO, Izuka OM, Ejekam, C. HIV/AIDS-related knowledge, attitudes and uptake of HIV testing services: a comparative study of male and female secondary school students in Lagos, Nigeria. West Afr J Med 2019;36:222-31. https://pubmed.ncbi.nlm.nih. gov/31622484/

35. Ekici G, Kurt H. Öğretmen Adaylarının "AIDS" Kavramı Konusundaki Bilişsel Yapıları: Bağımsız Kelime İlişkilendirme Testi Örneği. Türkiye Sosyal Araştırmalar Derg 2014;183:267306. https://dergipark.org.tr/tr/download/article-file/200593

36. Oğuzkaya Artan M, Baykan Z. Kayseri'deki Sağlık hizmetleri meslek yüksekokulu öğrencilerinin cinsel yolla bulaşan hastalıklar konusundaki bilgi düzeyleri ve bunu etkileyen faktörler. Türk Hijyen ve Deneysel Biyoloji Derg 2010;67:127-33. https:// dergipark.org.tr/en/download/article-file/1871227

37. Caetano ME, Linhares IM, Pinotti JA, Da Fonseca AM, Wojitani $\mathrm{MD}$, Giraldo PC. Sexual behavior and knowledge of sexually transmitted infections among university students in Sao Paulo, Brazil. Int J Gynecol Obstet 2010;110:43-6. [CrossRef]

38. Karabulutlu Ö, Kılıç M. Üniversite öğrencilerinin cinsel sağlık ve üreme sağlığı hakkındaki bilgi düzeyilerinin belirlenmesi. Anadolu Hemşirelik ve Sağlık Bilimleri Derg 2011;14:39-45. https:// dergipark.org.tr/tr/download/article-file/29495 